\title{
Indirect cooling of the cutting tool with a pumped two-phase system in turning of AISI 1045 steel
}

\author{
Rubens R. Ingraci Neto ${ }^{1}$ - Vicente L. Scalon ${ }^{1}$ Arthur A. Fiocchi ${ }^{1} \cdot$ Luiz E. A. Sanchez $^{1}$
}

Received: 10 November 2015 / Accepted: 9 March 2016 /Published online: 31 March 2016

(C) Springer-Verlag London 2016

\begin{abstract}
The elimination of cutting fluids' usage is one of the great challenges of sustainable manufacturing. Various devices and alternative techniques have been developed, but their results are limited, as well as their commercial applications. Most of them require drastic changes in the cutting tools or machine tools, or operate with nonevaporative cooling cycles, with low cooling capacity. The aim of this study is to present a device that overcomes these limitations and stands as an alternative to the application of cutting fluid without sacrificing the performance of the machining. Thus, a toolholder is developed that enables the indirect cooling of the cutting tool with a pumped two-phase system using the coolant $\mathrm{R} 141 \mathrm{~b}$ (vaporization temperature of $32^{\circ} \mathrm{C}$ ). In this system, the geometry of the cutting tool is not changed and there is no direct contact with the refrigerant, so there is no contamination or piece cleaning necessity. Moreover, the system operates in a closed circuit with only 51 of coolant that does not require constant treatment. The performance of the proposed method of internal cooling is evaluated by turning tests of AISI 1045 steel under conditions of continuous and interrupted cut. The turning tests compare the lives of the uncoated cemented carbide cutting tools, their temperatures, and wear mechanisms acting during machining with the internal cooling method, or cutting fluid or dry cutting. The results show that the internal cooling is able to extend the life of cutting tools by $58 \%$ in interrupted cutting and by $7 \%$ in continuous cutting in relation to the cutting fluid application and by 13 and by $45 \%$ in relation to the interrupted and continuous dry cutting,
\end{abstract}

Luiz E. A. Sanchez

sanchez@feb.unesp.br

1 Department of Mechanical Engineering, Sao Paulo State University Unesp, 17033-360 Bauru, SP, Brazil respectively. The thermal analysis indicates that the internal cooling method reduces the average surface temperature of the contact zone by $10 \%$ when compared to dry cutting. This device has a great possibility of use by the industry because is an effective and environmentally friendly technology.

Keywords Internal cooling $\cdot$ Cutting fluid $\cdot$ Dry cutting · Cutting tool wear $\cdot$ Turning

\section{Introduction}

The cutting tools used in machining processes are subjected to high temperatures and cutting forces that lead to wear, thus resulting in the production of workpieces noncompliant with design specifications. High-quality finish and dimensional accuracy combined with high productivity and low environmental impact depend on factors such as cutting fluids, type of material, and cutting tool geometry [1]. By combining a lubricating effect and cooling capacity, cutting fluids can extend the life of cutting tools and help remove chips [2].

While cutting fluids partially solve machining needs, they cause environmental problems and health risks. Therefore, cutting fluids require systems for storage, treatment, and recycling when they are discarded. Previous studies [3, 4] have demonstrated that the highest consumption of tap water in machining processes is related with the use of cutting fluids, mainly for cleaning machined workpieces. Cutting fluids also contain biocidal compounds to prevent the growth of fungi and bacteria. However, these compounds are harmful to the health of operators because they release formaldehydes. Operators exposed to cutting fluid and its fumes may develop allergic dermatitis and respiratory diseases as reported by Burton et al. [5-7]. A study presented by Trafny [8] revealed the presence of biofilms in cutting fluids, formed by fungi and 
nontuberculous mycobacteria that cause hypersensitivity pneumonitis and are not eliminated by conventional biocides, and that, moreover, may be stored in the system's metal components.

The best way to eliminate all the problems associated with the application of cutting fluids is by dry cutting, when this method achieves the required quality in a suitable production time and with an acceptable tool life [2]. Dudzinski et al. [9] stated that in order to ensure a stable and continuous cutting tool wear compatible with automated machining systems, the temperature in the cutting area during dry cutting must not reach critical values. Jianxin et al. [10] performed wear tests at high temperatures and showed that the wear of carbide tools at temperatures below $600{ }^{\circ} \mathrm{C}$ occurs mainly by abrasion, plastic deformation, and removal of the cobalt binder by dislodgement of WC particles. The intense oxidation that occurs above this temperature embrittles the tool's surface layer. When the temperature exceeds $700{ }^{\circ} \mathrm{C}$, the diffusion between the chip and the cemented carbide intensifies, resulting in the formation of a layer of material adhered to the surface of the tool and, hence, pulling out of the cemented carbide substrate $[11,12]$. Therefore, dry cutting performed simply by discontinuing the application of cutting fluid is difficult and requires complementary solutions. The various alternatives commonly include the use of solid lubricants, water or vapor spraying, cryogenic cooling, or indirect cooling methods [9]. Yildiz et al. [13] and Dhar et al. [14] reported interesting results about cryogenic cooling techniques. Çakir et al. [15] made comparisons of gases' applications to wet and dry cutting. Ahmed et al. [16] applied liquid nitrogen through a modified toolholder to cool the cutting tool and were capable of extending the cutting tool life. New technologies in the composition of cemented carbide, substrate grain refinement, and advances in coating preparation and deposition methods also contribute to increase the wear resistance of cutting tools. As for the benefits of coatings, they act as a thermal barrier, withstand higher pressures, and hinder crack propagation [17, 18].

One of the most promising methods to replace the use of cutting fluids is the indirect cooling of cutting tools. The first indirect cutting tool cooling method used a heat pipe containing water and was proposed in 1969. This method used natural convection associated with heat transfer with water phase change to cool the cutting tool. The vapor formed in this device could also be directed to the cutting area or recirculated using a condensing process $[19,20]$.

Zhao et al. [21] and Zhao et al. [22] have developed mathematical models to assess indirect cooling methods, considering their action as heat sinks positioned underneath cutting tools, which can extract from 25 to $45 \mathrm{MW} / \mathrm{m}^{2}$. According to these models, these systems are presumably able to reduce average temperatures at uncoated carbide cutting tool rake faces by 50 to $100{ }^{\circ} \mathrm{C}$. This reduction implies an increase of over $15 \%$ in the life of these tools. Chiou et al. [23] performed tests with heat pipes in turning AISI 1020 and AISI 1040 steel with $1 \mathrm{~mm}$ depth of cut, $0.1 \mathrm{~mm} / \mathrm{rev}$ feed rate, and $30 \mathrm{~m} / \mathrm{min}$ cutting speed, using uncoated cutting tools. Those tests revealed a $60{ }^{\circ} \mathrm{C}$ reduction in the average temperature at the rake surface, with the generation of $15.7 \mathrm{~W}$ during machining. In a similar study employing a heat pipe that could eliminate $40 \mathrm{MW} / \mathrm{m}^{2}$, a numerical analysis indicated a decrease of $75^{\circ} \mathrm{C}$ in the maximum temperature at the tool rake face, during a turning generating $20 \mathrm{~W}$ [24]. Liang et al. [25] placed a heat pipe on the tool; the maximum temperature of the cutting tool was reduced by $96.6{ }^{\circ} \mathrm{C}$ when turning AISI 1045 steel at a $175.84 \mathrm{~m} / \mathrm{min}$ cutting speed, $0.7 \mathrm{~mm}$ depth of cut, and $0.1 \mathrm{~mm} / \mathrm{rev}$ feed rate.

Despite the good results that have been reported, heat pipes are difficult to adapt to toolholders and to conventional cutting tools because they have to be placed in close proximity to cutting edges, thus reducing the use of this method. Alternative cooling methods may be feasible if the device is affordable and if it can be integrated with any conventional machine tool [26]. Ferri et al. [27] and Sun et al. [28] developed a toolholder with indirect cooling using a machined cemented carbide tool at its base, to which was attached a steel support with microchannels, creating a chamber between the bottom surface of the tool and the top of the support through which $0.3 \mathrm{l} / \mathrm{min}$ of water circulated. This system lowered the chip temperature of an aerospace aluminum alloy by $25{ }^{\circ} \mathrm{C}$ during turning at a cutting speed of $300 \mathrm{~m} / \mathrm{min}$. In another study [29], the lower surface of a cemented carbide tool coated with a $12-\mu \mathrm{m}$ diamond layer was placed in contact with $0.3 \mathrm{l} /$ min of ethylene glycol-based coolant. In a turning test of a titanium alloy at $80 \mathrm{~m} / \mathrm{min}$ cutting speed, $0.2 \mathrm{~mm} / \mathrm{rev}$ feed rate, and $1 \mathrm{~mm}$ depth of cut, the tool life was $63 \%$ longer than in dry cutting and the average temperature of the chip surface decreased by about $13{ }^{\circ} \mathrm{C}$. However, the cooling capacity of this system is limited by the nonevaporation of the coolant. To overcome this limitation, another system was developed with a microchannel heat exchanger positioned under the cutting tool, through which liquid nitrogen (LN2) circulated at a flow rate of $0.04 \mathrm{l} / \mathrm{min}$. The $\mathrm{LN} 2$ cooled the cutting tool by using the latent heat of vaporization of nitrogen. When this method was compared with machining using $5 \mathrm{l} / \mathrm{min}$ of cutting fluid, the tool life provided by the proposed method was ten times longer. However, at a cutting speed of $200 \mathrm{~m} / \mathrm{min}$, the cooling capacity of the heat exchanger was impaired by the formation of a vapor film inside it, which caused an insulating effect and resulted in similar values for both methods [26].

In a study conducted by the group of researchers of this work [30,31], a two-phase cooling device was developed for the cutting tool. A copper plate located underneath the cutting tool acted as a heat sink between the lower portion of the cutting tool and a chamber in which the coolant circulated. The coolant, in turn, vaporized upon contact with the copper 
heat sink that cooled the cutting tool. The vapor exiting from the interior of the toolholder condensed and recirculated in a closed loop. Although this prototype increased the cutting tool life by about $32 \%$ when compared to dry cutting, some difficulties were detected during its operation. The decline in the cooling capacity during the operation led us to infer that a vapor film was formed in the upper portion of the evaporation chamber, owing to the chamber's unsuitable geometry. Moreover, the copper plate reduced the stiffness of the device, deforming in response to machining forces. Other recent studies on indirect cooling methods based on fluid recirculation inside the toolholder have shown satisfactory results only when compared to dry cutting $[27,29]$.

Although their good results the elimination of cutting fluid application poses the greatest challenge in the field of machining. Moreover, most of recent studies required modifications in cutting tools, or did not use phase-change fluids (lower cooling capacity), or did not recirculate the coolant.

This paper presents a new design of the internally cooled toolholder that will enable its use in applications in which cutting fluids are conventionally employed, without affecting the performance of the machining. The indirect cooling of the cutting tool with a pumped two-phase cooling system operates without changing the geometry of the insert and in a closed loop circulation. The new cooling system aims not only to reduce costs and impacts on human health and the environment but also to achieve a performance similar or superior to that of conventional machining with the application of cutting fluid. To evaluate this situation, experimental tests are performed comparing tool life, cutting tool temperature profiles, machining forces, and surface roughness with internal cooling, flood application of cutting fluid, and dry cutting in turning AISI 1045 steel.

\section{Experimental setup}

Figure 1 presents the designed toolholder, its parts, and the closed loop circuit. The coolant circulates in the internal channels of the toolholder and vaporizes when in contact with the silver interface that cools the cutting tool during the machining. It forms with the inlet channel a tilted annular section of $30 \mathrm{~mm}^{2}$ that prevents vapor entrapment and has $106 \mathrm{~mm}^{2}$ of heat transfer surface. The bottom of the cutting tool, i.e., $54 \mathrm{~mm}^{2}$, is in contact with the silver interface. The toolholder has the following characteristics: $90^{\circ}$ cutting edge angle $(\chi \mathrm{r}), 0^{\circ}$ rake angle $(\gamma), 0^{\circ}$ cutting edge inclination angle $(\lambda \mathrm{s})$, and a square section of $20 \mathrm{~mm}$. A removable support facilitates the machining of the toolholder and aids the insertion of three microthermocouples (positions $T 1, T 2$, and $T 3$ ) in contact with the cutting tool. The condenser is exposed to forced air convection at $25{ }^{\circ} \mathrm{C}$ to condense the vapor into liquid, which is stored in the accumulator and, then, is pumped back into the toolholder.

The coolant, Dupont R141b, recirculates via a peristaltic pump at a flow rate of $1.78 \mathrm{l} / \mathrm{min}$, i.e., a mass flow rate of $37.08 \mathrm{~g} / \mathrm{s}$. The vaporization temperature of this fluid is $32^{\circ} \mathrm{C}$ at $101.3 \mathrm{kPa}$. The cooling system uses just 51 of R141b.

Figure 2 shows the toolholder with its coolant inlet and outlet tubes, thermocouples, and Kistler 9257BA 3component dynamometer attached to the CNC ROMI CENTUR 30D $10 \mathrm{~kW}$ lathe.

Data acquisition modules, NI-9207 and NI-9214, connected to the cDAQ-9188, record the machining force and the temperatures of the thermocouples using LabVIEW 6.1 software, all from National Instruments.

The turning tests aim to evaluate the cutting tool performance with internal cooling (IC) system and compare it with that of dry cutting (Dry), and especially with that of flood cutting fluid application (CF) in the machining of AISI 1045 steel. The cutting fluid is a semi-synthetic ROCOL Ultracut 370 diluted in water, 1:10, applied at a flow rate of $10 \mathrm{l} / \mathrm{min}$. Table 1 describes the cutting conditions of the turning tests, which involve both continuous and interrupted turning; Fig. 3 depicts the geometric characteristics of the test specimens for continuous and interrupted turning. The samples for continuous turning, hereinafter referred to as AISI 1045-C, have a length of cut (LC) of $155 \mathrm{~mm}$. The designation AISI 1045-I refers to the test specimens for interrupted cutting, each one comprises 10 segments of $20 \mathrm{~mm}$, with a LC of $200 \mathrm{~mm}$. The uncoated cemented carbide cutting tools are classified as ISO M10-M25, TPUN 160308, grade IC20, manufactured by
Fig. 1 Toolholder with internal cooling: a section view, b diagram of cooling system, and $\mathbf{c}$ silver interface inserted in the toolholder

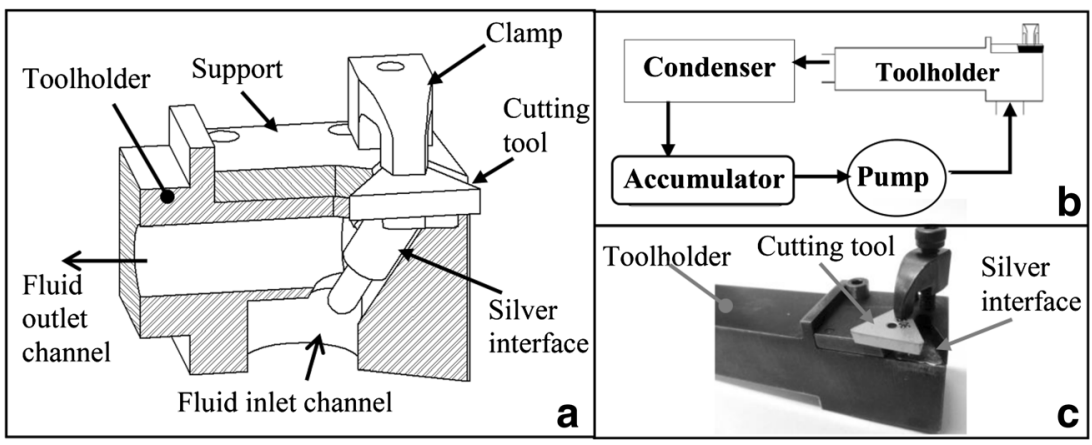


Fig. 2 View of a interrupted turning test assembly and $\mathbf{b}$ toolholder installed on the lathe

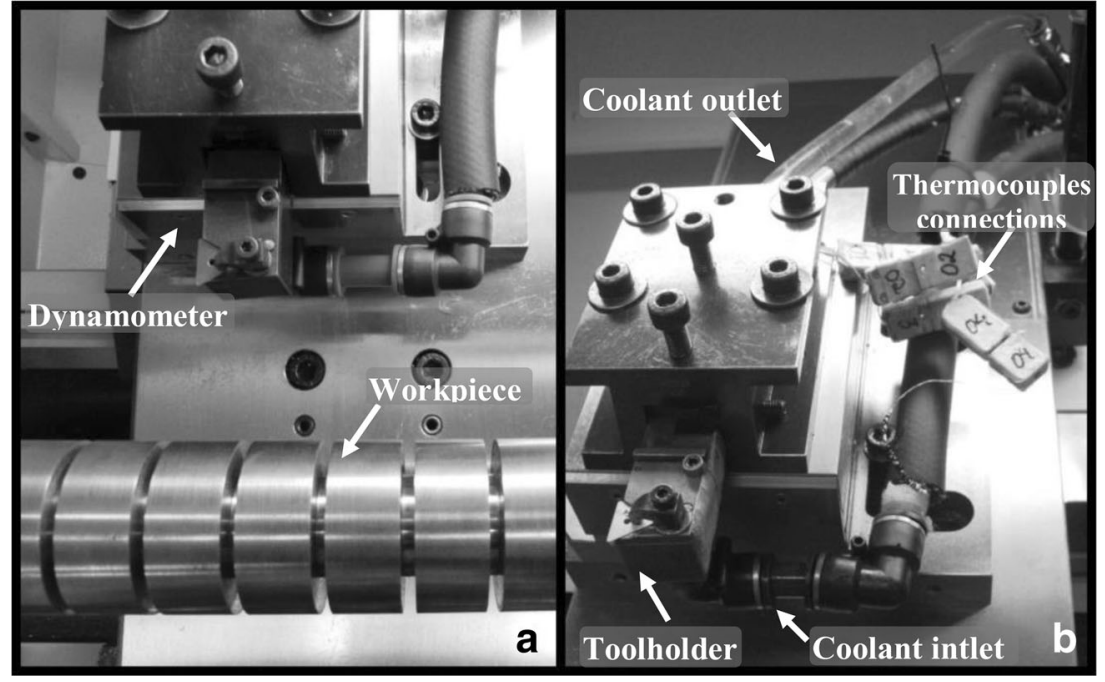

ISCAR. Those uncoated cemented carbides are chosen to exclude the coating and chip breaker interference from the results, i.e., to simplify the wear analysis.

Table 2 describes the chemical composition and physical properties of AISI 1045 steel.

At the end of each turning test, the flank wear and the maximum crater wear depth (KT) of the cutting tools is measured under a Nikon SMZ800 optical microscope. The surface roughness of the machined workpieces is measured using a portable Taylor Hobson Surtronic 3+ roughness tester. For each cutting condition and cooling method, the tests are interrupted when the cutting tools reach their maximum flank wear, $V_{B} \max \geq 0.6 \mathrm{~mm}$, or average flank wear, $V_{B} \geq 0.3 \mathrm{~mm}$, or if they fracture. After testing all the cutting conditions, the cutting tools are examined under a LEO ZEISS 440 scanning electron microscope (SEM).

\section{Results and discussion}

The cutting fluid application requires systems for pumping hundreds of liters per hour, storage, monitoring, treatment, maintenance of the cutting fluid quality, and for recycling it when it is discarded. Its use represents tap water consumption mostly

Table 1 Cutting conditions for all cooling methods

\begin{tabular}{lllll}
\hline Condition & Material & $V_{c}(\mathrm{~m} / \mathrm{min})$ & $f(\mathrm{~mm} / \mathrm{rev})$ & $a_{p}(\mathrm{~mm})$ \\
\hline 1 & AISI 1045-I & 100.00 & 0.20 & 1.00 \\
2 & AISI 1045-I & 100.00 & 0.40 & 1.00 \\
3 & AISI 1045-I & 80.00 & 0.20 & 1.00 \\
4 & AISI 1045-I & 80.00 & 0.40 & 1.00 \\
5 & AISI 1045-C & 100.00 & 0.20 & 1.00 \\
6 & AISI 1045-C & 80.00 & 0.20 & 1.00 \\
\hline
\end{tabular}

$V_{c}$ cutting speed, $f$ feed, $a_{p}$ depth of cut because the contaminated pieces need to be washed. Moreover, the environmental problems, health risks, and health precautions associate with its consumption turning its traditional usage in an expensive and very dangerous choice to the future.

The indirect cooling system designed as an alternative to the cutting fluid application has only 51 of refrigerant operating in a closed loop at a flow rate lower than $21 / \mathrm{min}$ with a $100-\mathrm{W}$ pump. As the device operates with a low refrigerant volume, the pump, the condenser, the cooler, and the accumulator comprise a compact system with lower cost of installation and lower energy consumption. In addition, there is no fluid maintenance or treatment. The cost reduction of the delineated device in contrast to cutting fluid application can be even greater when one considers there is no need of washing the pieces, since they are not contaminated. Furthermore, the closed loop configuration, without fluid leaking to the atmosphere, makes it an environmentally friendly technology and harmless to the operator.

The presented cooling system operates with R141b, because its application has stopped according to Montreal Protocol; due to its ozone depletion potential (ODP) of 0.11

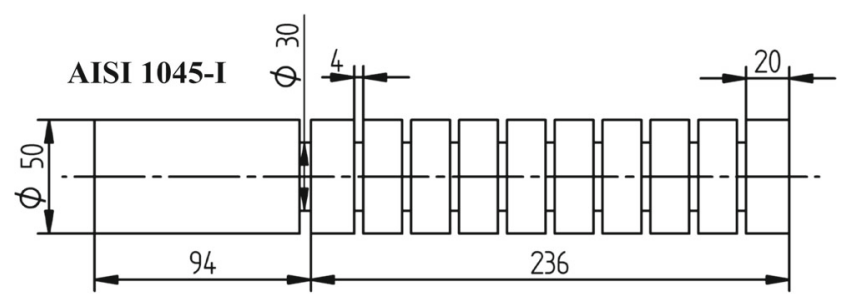

AISI 1045-C

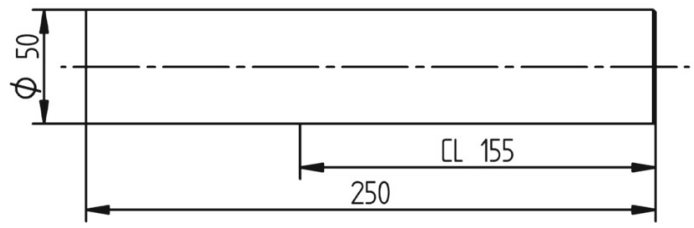

Fig. 3 Geometries of the specimens 
Table 2 Composition (wt\%) and physical properties of AISI 1045 steel [38]

AISI 1045

\begin{tabular}{|c|c|c|c|c|c|c|c|}
\hline$C$ & $\mathrm{Si}$ & $\mathrm{Mn}$ & $\mathrm{Cr}$ & $\mathrm{Nb}$ & $\mathrm{Ni}$ & $N$ & $W$ \\
\hline 0.45 & 0.40 & 0.65 & 0.40 & 0.10 & 0.40 & 0.04 & 0.05 \\
\hline \multicolumn{4}{|c|}{ Modulus of elasticity (GPa) } & 205 & & & \\
\hline \multicolumn{4}{|c|}{ Density $\left(\mathrm{Kg} / \mathrm{m}^{3}\right)$} & 7844 & & & \\
\hline \multicolumn{4}{|c|}{ Thermal conductivity (W/m.K) } & 49.8 & & & \\
\hline \multicolumn{4}{|c|}{ Specific heat capacity (J/kg.K) } & 486 & & & \\
\hline
\end{tabular}

and greenhouse warming potential (GWP) of 725 , other cooling alternatives should be used. The first usual alternative, R123b (1,1,1-trifluoro-2,2-dichloroethane, CAS No 306-832) with a boiling point of $28^{\circ} \mathrm{C}$, will be phased out by 2020 . Therefore, recently, other alternative refrigerants have been presented as the HFO-1233zd (trans-1-chloro-3,3,3trifluoropropene, CAS No 102687-65-0, ODP of 0.00034, and GWP of 1) with a boiling point of $18^{\circ} \mathrm{C}$ and the HFO1336mzz also known as DR-2 (1,1,1,4,4,4-hexafluoro-2-butene, CAS No 692-49-9, zero ODP, and GWP of 2) with a boiling point of $33.4{ }^{\circ} \mathrm{C}$ and latent heat of $165.67 \mathrm{~kJ} / \mathrm{kg}$ [32]. Both refrigerants are nonflammable and are considered environmentally friendly alternatives to R $123 \mathrm{~b}$, being classified as class A1 safety by ASHRAE Standard 34. According to their thermophysical properties, the most suitable fluid for this indirect cooling application in the developed device is the HFO1336mzz.

Figure 4 shows the volume of removed material, maximum crater wear depth, average parameters of surface roughness, resultant cutting force, and mean temperature at thermocouple $T 1$ (that is at $1 \mathrm{~mm}$ from the cutting edge) for each cutting condition. In this figure, an asterisk $(*)$ identifies fracture of the cutting tool and $\mathrm{IC}=$ internal cooling, dry $=$ dry cutting, and $\mathrm{CF}=$ cutting fluid application. As can be seen, the internal cooling method provides the greater cutting tools' lives (volume of removed material) in most of the tested conditions. Even under the inferior conditions, its performance is consistently close to optimal. In the specific case of interrupted cutting (conditions 1 to 4 ), the third condition with IC results in the best performance $\left(V_{c}=80 \mathrm{~m} / \mathrm{min} ; f=0.2 \mathrm{~mm} / \mathrm{rev}\right.$ and $a$ $p=1.0 \mathrm{~mm}$ ). The IC method also provides the greatest volume of removed material in condition 6 among the continuous turning tests.
Fig. 4 Results for different machining conditions and cooling method: a volume of removed material, $\mathbf{b}$ maximum crater wear depth; $\mathbf{c}$ average roughness $\mathrm{Ra}, \mathbf{d}$ average roughness $\mathrm{Rz}_{\mathrm{DIN}}$, $\mathrm{e}$ resultant cutting force, and $\mathbf{f}$ cutting tool temperature at $\mathrm{T} 1$. IC internal cooling, Dry dry cutting, $C F$ cutting fluid application
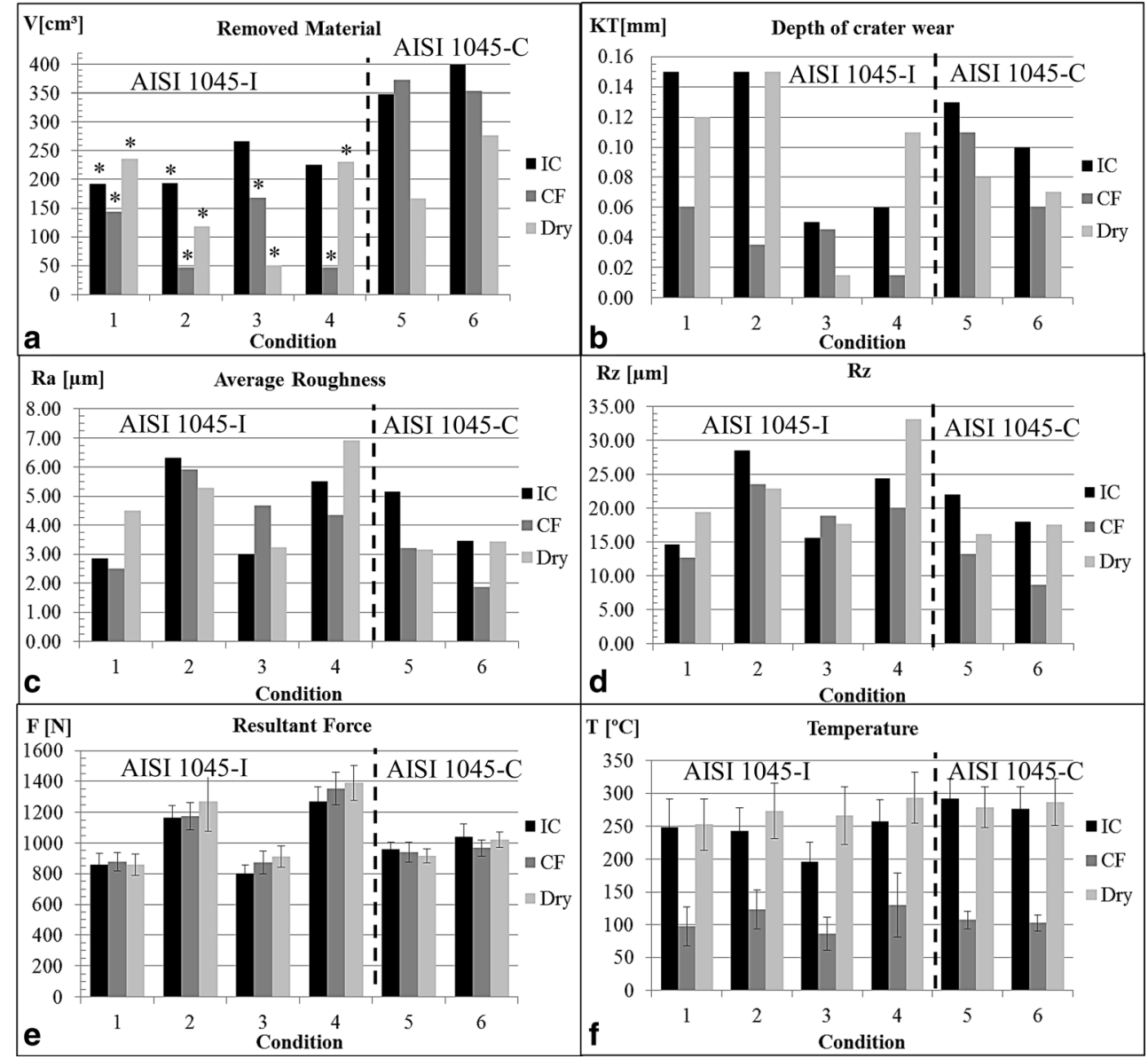
Figure 5 exhibits the chipping of the cutting tools when cutting fluid is applied, probably owing to the thermal stresses generated during interrupted cutting. Nevertheless, under conditions 5 and 6 of continuous turning, there is no chipping of the cutting tools even under the application of cutting fluid.

Still with regard to Fig. 4, note that the temperature under the $\mathrm{CF}$ method reaches about $100{ }^{\circ} \mathrm{C}$, which is close to the vaporization temperature of water, demonstrating the significant thermal gradient to which the cutting tool is subjected.

As proposed by Bhatia et al. [33], Eq. 1 can be used to estimate the thermal stress in interrupted cutting.

$\sigma=\frac{1}{1-\vartheta} E \cdot \beta \cdot \Delta T$

In Eq. $1, \sigma$ represents stress, given in megapascal; $v$ is Poisson's coefficient, which is assumed to be 0.22 for cemented carbide; $E$ is the modulus of elasticity, of $640 \mathrm{GPa} ; \beta$ is the linear thermal expansion coefficient of the cutting tool material, $5.5 .10^{-6} /{ }^{\circ} \mathrm{C}$; and $\Delta T$ is the temperature variation. As a result of the application of this equation, the estimated thermal stress for a variation of about $700{ }^{\circ} \mathrm{C}$ is $3.159 \mathrm{GPa}$. This tensile stress is close to the value of the tensile yield strength of cemented carbide and may therefore lead to crack propagation as indicated by Bouzakis et al. [17].
The interrupted turning tests with uncoated cemented carbide cutting tools indicate that intermittent cutting conditions, as those usually observed in the machining cycles, like roughing cycle, lead to high thermal stress that can be avoided with the use of indirect cooling method instead of applying the cutting fluid.

As suggested in Fig. 4b, the use of cutting fluid reduces the crater wear. This behavior can be further confirmed by comparing the final depth of crater wear and the volume of removed material up to the end of tool life under this group. The dry cutting and internal cooling conditions have the higher values of crater wear. The effect of this type of wear is to weaken the cutting edge; however, in conditions 3 and 4 of internal cooling, there is no pronounced crater wear and the life of the cutting tool is determined by flank wear.

It is known that the greater severity of interrupted cutting compared to that of continuous cutting can reduce the cutting tool life. During interrupted cutting, the cutting tool undergoes greater oxidation because of its contact with air when no material is cut. In this situation, the rapid loading and unloading of the cutting tool also generates undesirable thermal gradients. At the same time, tensile stresses are expected to develop owing to the differences in the contraction of the cemented carbide and of the chip adhered to the surface of cutting tools. In addition, interrupted cutting
Fig. 5 Chipping of the cutting tools in interrupted turning with cutting fluid

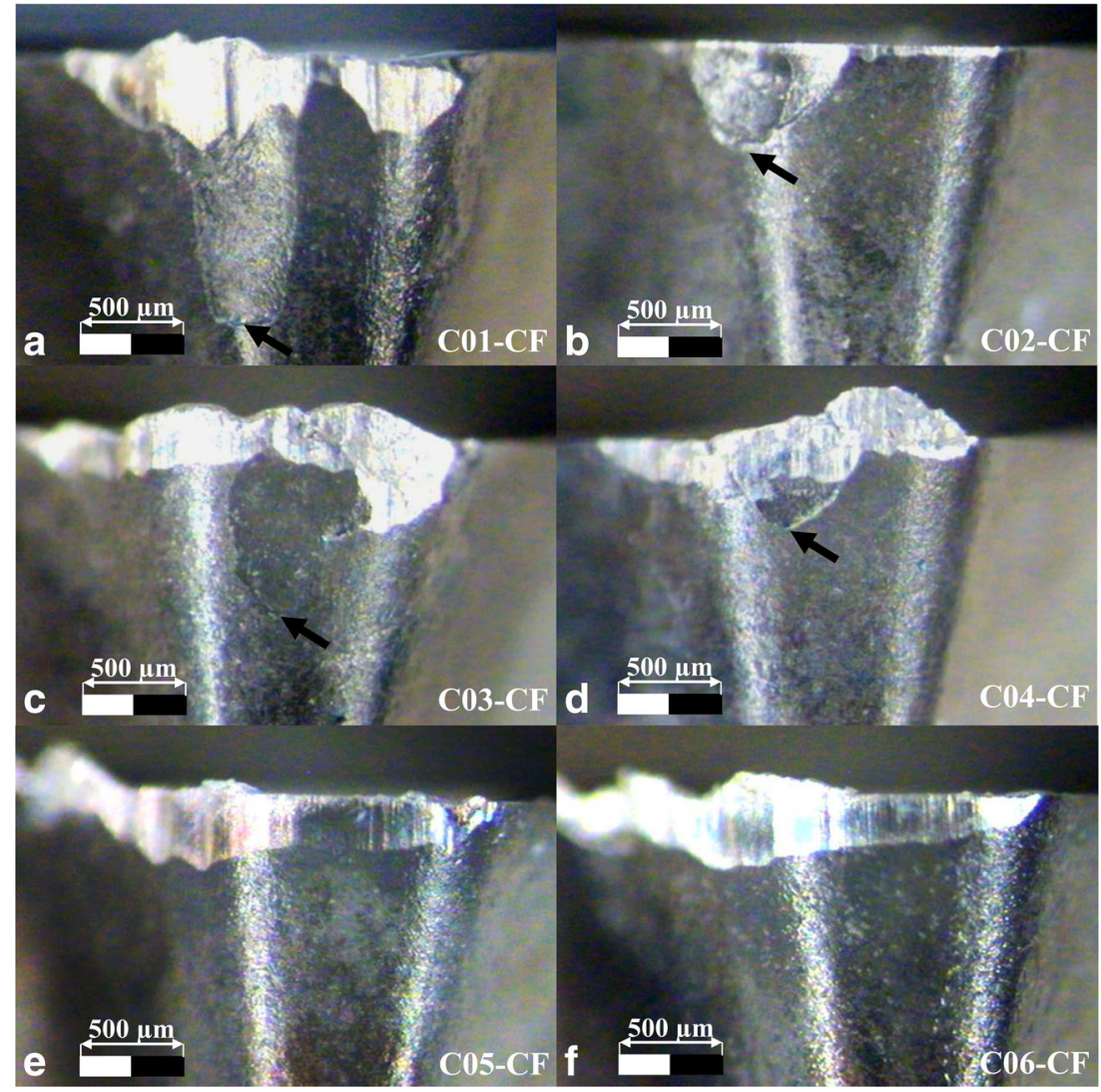




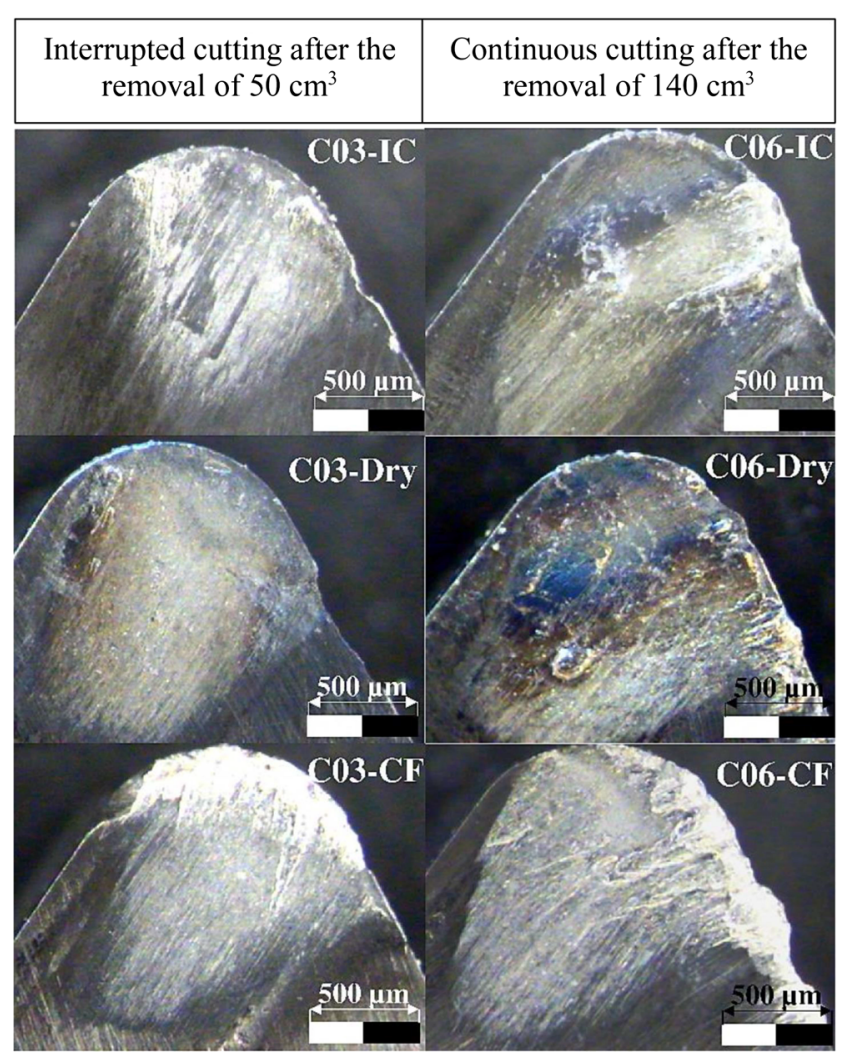

Fig. 6 Tool wear in interrupted $(\mathrm{CO})$ and continuous $(\mathrm{CO})$ cutting after removing 50 and $140 \mathrm{~cm}^{3}$, respectively. $I C$ internal cooling, Dry dry cutting, $C F$ cutting fluid application

causes the inversion of compressive stress to tensile stress after instantaneous relaxation occurs in the portions of interrupted cut. These factors lead to rapid abrasive wear, crater formation, and crack propagation with chipping of the cutting edges.
Figure $4 \mathrm{c}, \mathrm{d}$ demonstrates the variation in surface roughness values, but it is not possible to establish a correlation with the cooling methods.

An analysis of the six cutting conditions illustrated in Fig. $4 \mathrm{e}$ indicates that the resultant machining forces in each condition present similar values, suggesting their strong correlation with the cutting parameters rather than with the cooling methods. However, in condition 3 with internal cooling, the resultant force and average temperature are lower than that during dry cutting, indicating a difference between wear mechanisms. In dry cutting, the greater adhesion of material on the cutting tool increases the crater wear, resulting in higher cutting forces and temperature, enhancing the tendency for cutting tool chipping during interrupted turning. With internal cooling, the predominant wear mechanism is abrasion, as pointed out by Fig. 6 and by the SEM micrographs. In this case, the removal of heat by the internal cooling method (IC) reduces the temperature of the cutting tool, allowing it to retain its hardness and thus mitigating the abrasion mechanism.

Figure 6 shows the cutting tool wear under the three cooling methods, in both interrupted (C03) and continuous (C06) cutting, after removing 50 and $140 \mathrm{~cm}^{3}$, respectively. The micrographs offer evidence that for internal cooling method, the material adhered to the cutting tool is unstable, adhering weakly to the tool rake face and then it is removed during machining without pulling out the substrate material. The lowest temperature in the cutting tool is obtained when applying the cutting fluid, followed by internal cooling. A greater adhesion and deformation of material on the cutting tool, as well as higher oxidation, occur during dry cutting, as expected under this condition.

Figure 7 illustrates the average machining forces and temperatures for the different cooling methods in condition 3 of
Fig. 7 Results for $\mathbf{a}, \mathbf{b}$ average machining forces and $\mathbf{c}, \mathbf{d}$ temperatures in conditions 3 and 6. IC internal cooling, Dry dry cutting, $C F$ cutting fluid application

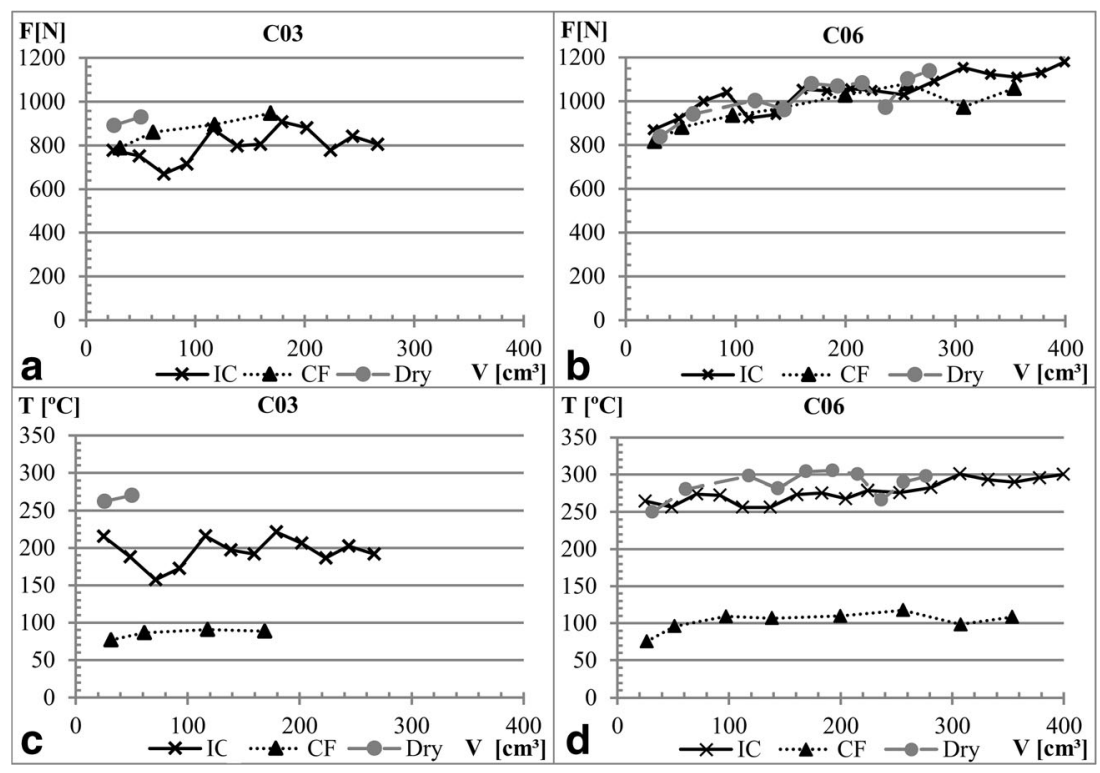




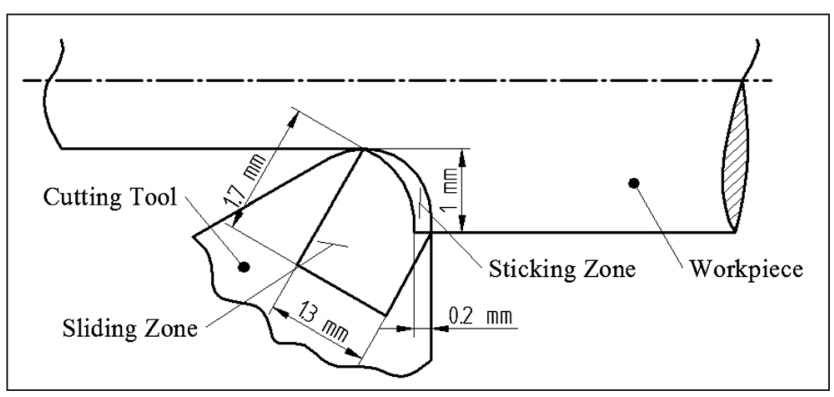

Fig. 8 Areas of contact between chip and tool

interrupted cutting and in condition 6 of continuous cutting, from the beginning to the end of life of the cutting tools. Note that, regardless of the cooling method, the values of the machining forces are similar, while the temperatures recorded by $T 1$ with IC are about 80 and $50{ }^{\circ} \mathrm{C}$ lower than that in interrupted dry cutting (Fig. 7c) and in continuous dry cutting (Fig. 7d), respectively. As expected, the increase of the cutting tools' wear (volume of removed material) leads to greater machining forces and temperatures.

A thermal simulation compares the cutting tool temperature profile with the internal cooling method with that of dry cutting in condition 6 of continuous cutting. The thermal study uses the commercial software COMSOL® 5.0 to perform a heat conduction analysis. The computational domain of the mesh includes the cutting tool and the silver interface. The mesh contains 350,686 tetrahedral elements, the minimum element size is $3.63 \mu \mathrm{m}$, and the mesh volume is $809.4 \mathrm{~mm}^{3}$. The model has two distinct heat flow regions, as can be seen in Fig. 8. A microscopic analysis indicated that the lengths of the chip-tool contact zones are the same for IC and for the dry cutting condition, i.e., a sticking zone of $0.2 \mathrm{~mm}^{2}$ and a sliding zone of $1.71 \mathrm{~mm}^{2}$. The heat fluxes and the temperature profiles of the models are determined by means of an iterative process for a stationary study, i.e., a steady state of heat conduction. This iterative process adopts that the heat fluxes in contact zones are constant and the same in both cooling methods and that the temperatures recorded experimentally must be similar to the results from the simulation for the positions of the thermocouples. For purposes of simplification, all the boundaries of the model are considered adiabatic, except for the regions where chip and cutting tool are in contact, which are the regions of heat flow, and for the portion of silver interface in contact with the coolant. The temperature
Table 4 Physics properties of R141b

\begin{tabular}{ll}
\hline Physical property at $32{ }^{\circ} \mathrm{C}$ & Value \\
\hline Mass density of saturated vapor $\left(\rho_{v}\right)$ & $4.852 \mathrm{~kg} / \mathrm{m}^{3}$ \\
Heat of vaporization $\left(h_{f g}\right)$ & $223 \mathrm{~kJ} / \mathrm{kg}$ \\
Surface tension $(\sigma)$ & $0.01731 \mathrm{~N} / \mathrm{m}$ \\
\hline
\end{tabular}

of the lower portion of the silver interface that is in contact with the coolant is set at $32^{\circ} \mathrm{C}$ for the internal cooling method, which is the evaporating temperature of the coolant, and $110^{\circ} \mathrm{C}$ for dry cutting, as recorded by thermocouple $4(T 4)$. Table 3 shows thermal simulation results and the average experimental temperatures recorded by the three thermocouples that are in contact with the cutting tool when $120 \mathrm{~cm}^{3}$ of material are removed. Those temperatures represent an intermediate wear stage of the cutting tools similar to those presented previously in Fig. 6.

The thermal conductivity adopted for the cemented carbide is $100 \mathrm{~W} / \mathrm{mK}$, the specific heat used is $430 \mathrm{~J} / \mathrm{kg} . \mathrm{K}$, and the density is $11,900 \mathrm{~kg} / \mathrm{m}^{3}$ [12]. The assumed thermal conductivity of the silver interface is $419 \mathrm{~W} / \mathrm{mK}$, its specific heat is $234 \mathrm{~J} / \mathrm{kg} . \mathrm{K}$, and its density is $10,491 \mathrm{~kg} / \mathrm{m}^{3}$.

The result of the thermal simulation indicates that the heat flux is $40 \mathrm{MW} / \mathrm{m}^{2}(8 \mathrm{~W})$ in the sticking zone and $42.5 \mathrm{MW} / \mathrm{m}^{2}$ $(72.68 \mathrm{~W})$ in the sliding zone. Then, the total heat transfer from the chip to the cutting tool is $80.68 \mathrm{~W}$. These results are expected for these cutting parameters, as can be analytically predicted using the thermal models developed by Shaw [12] or by Komanduri and Hou [34-36].

Once that in internal cooling method the section of the silver interface in contact with the fluid is kept at $32{ }^{\circ} \mathrm{C}$, it is expected that the heat generated during the cutting have been dissipated through the coolant.

Actually, if Eq. 2, developed by Lienhard and Eichhorn [37], estimates the maximum heat flux $\left(q{ }^{\prime \prime}{ }_{\max }\right)$ extracted of a hot cylinder by a cross flow of saturated liquid, then, it is possible to estimate the maximum cooling capacity of the internal cooling system. Table 4 gives the physics properties of R141b.

$q^{\prime \prime}{ }_{\max }=\frac{\rho_{v} h_{f g} U_{\infty}}{\pi}\left[1+\left(\frac{4 \sigma}{\rho_{v} U_{\infty}^{2} D}\right)^{1 / 3}\right]$
Table 3 Experimental and simulated temperatures

\begin{tabular}{|c|c|c|c|c|c|c|}
\hline \multirow[t]{2}{*}{ Temperature $\left({ }^{\circ} \mathrm{C}\right)$} & \multicolumn{3}{|l|}{ C06-dry } & \multicolumn{3}{|l|}{$\mathrm{C} 06-\mathrm{IC}$} \\
\hline & Experimental & Simulated & Error $(\%)$ & Experimental & Simulated & Error $(\%)$ \\
\hline $\mathrm{T} 1$ & 300 & 293 & 2.39 & 250 & 237 & 5.49 \\
\hline $\mathrm{T} 2$ & 190 & 195 & 2.56 & 150 & 132 & 13.36 \\
\hline $\mathrm{T} 3$ & 120 & 133 & 9.77 & 75 & 71 & 5.63 \\
\hline
\end{tabular}


Fig. 9 Temperature profiles in cutting condition 6 for a dry cutting and $\mathbf{b}$ internal cooling

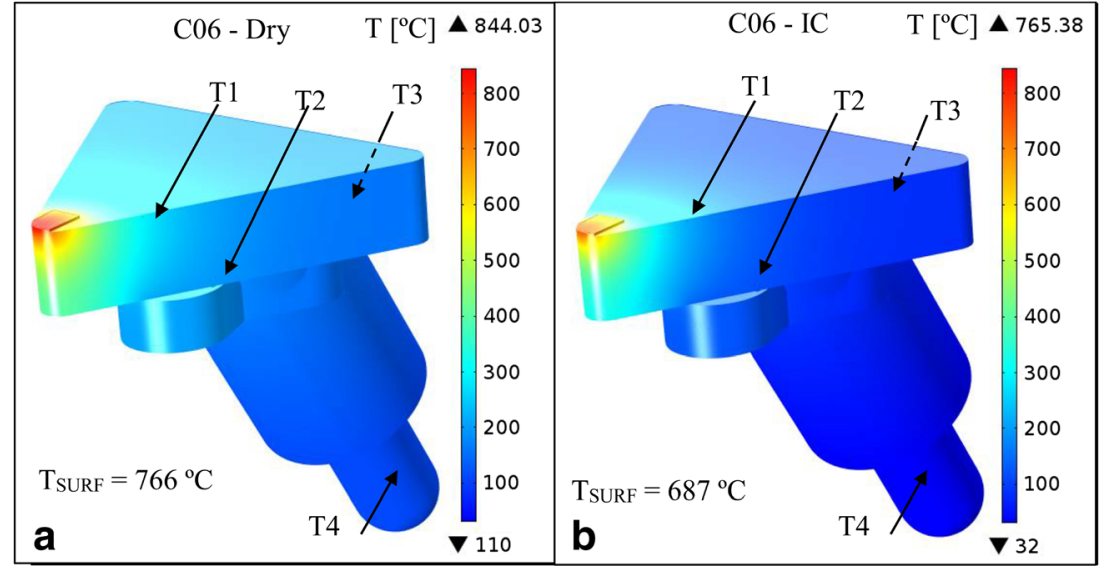

Equation 2 reveals a maximum heat flux of $909.36 \mathrm{~kW} / \mathrm{m}^{2}$, for a flow velocity $\left(U_{\infty}\right)$ of $1.028 \mathrm{~m} / \mathrm{s}$ and a silver cylinder of $3.5 \mathrm{~mm}$ of diameter $(D)$. Then, for a surface contact area of $106 \mathrm{~mm}^{2}$, the maximum cooling capacity of the system is $96.4 \mathrm{~W}$, versus $80.68 \mathrm{~W}$ generated during machining. This indicates that in $\mathrm{C} 06$ the internal cooling method is able to cool properly the cutting tool. However, at conditions with higher energy generation, the IC method probably has its efficiency limited.

Figure 9 illustrates the simulated temperature profiles of the cutting tools and silver interfaces, as well as points the positions of the thermocouples. The results indicate that the maximum temperature of the cutting tool with $\mathrm{IC}$ is $79^{\circ} \mathrm{C}$ lower than the maximum temperature reached in dry cutting. In addition, the average temperature in the surface area of contact between tool and chip $\left(T_{\text {SURF }}\right)$ is $687^{\circ} \mathrm{C}$ with internal cooling, i.e., $10 \%$ lower than in dry cutting $\left(766^{\circ} \mathrm{C}\right)$.

Because the average temperature at the surface of the cutting tool was below $700{ }^{\circ} \mathrm{C}$, the proposed internal cooling method may have been able to minimize the wear mechanisms that occur under this temperature range [10-12]. This thermal simulation comes from a simplified heat conduction problem combined with empirical results, as shown by the precision of the results on Table 3. Its main purpose is to support the evaluation of internal cooling effects on the cutting tool. Nevertheless, the results from the thermal analysis are similar to those reported in other studies of machining systems with indirect cooling of the cutting tool [21-29].

Fig. 10 SEM micrographs of the cutting tools for a C03-IC, b C03CF, $\mathbf{c}$ C03-Dry, and $\mathbf{d}$ QBSD of C06-CF. IC Internal cooling, Dry dry cutting, $C F$ cutting fluid application

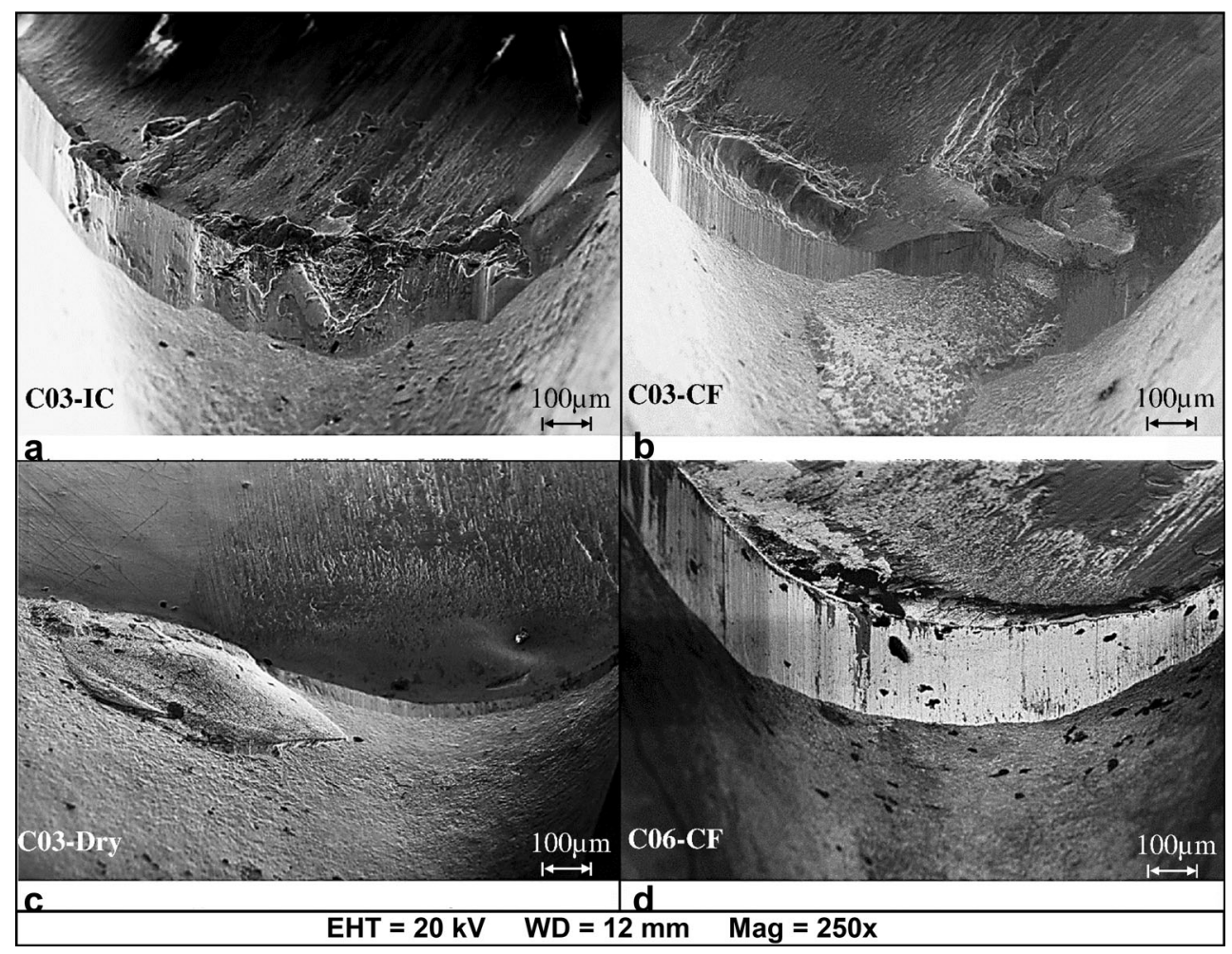


Figure 10 shows SEM micrographs of the cutting tools at the end of their lives. Figure 10a, d demonstrates that the main wear mechanism under those cutting conditions is abrasion. Although adherence also occurs, it does not seriously affect the cutting tools. Also, it is important to note the occurrence of chipping of the cutting edges under the cutting condition 3 with cutting fluid and dry (C03-CF and C03-Dry), as indicated in Fig. 10b, c, which is attributed mainly to thermal gradients and the intensity of the cutting forces. In Fig. 10d, obtained with four-quadrant backscattered electron detector (QBSD), dark spots can be seen, which are residues of cutting fluid.

\section{Conclusions}

The presented indirect cooling system operates in a closed loop, without fluid leakage or piece contamination, is designed for commercial cutting tools, and uses a phasechange coolant with greater cooling capacity. Unlike other devices, this one uses a pumped two-phase cooling system and achieves similar or even greater cutting tool life than that obtained in the conventional cutting fluid application method. These characteristics provide some advantages to this toolholder concept making it an environmentally friendly technology for industrial application.

In interrupted turning tests, the internal cooling is able to extend the cutting tools' lives by 58 and by $13 \%$ in relation to the cutting fluid application and dry cutting, respectively. In continuous cutting tests, the IC method is able to extend the cutting tool lives by 7 and by $45 \%$ in relation to the cutting fluid application and dry cutting, respectively.

The temperatures recorded by the thermocouples and the results of the thermal simulation demonstrate a reduction of $10 \%$ in the average temperature in the contact zone between chip and cutting tool with the internal cooling method when compared to dry cutting, thus confirming the longer lives of the cutting tools.

As a result, the developed device represents a real alternative to the traditional method of cutting fluid application, whose elimination is one of the major goals in the field of machining. The performances of other similar devices have been compared with dry cutting, with predictably superior results [23, 25, 27-29].

Lastly, because the indirect cooling device operates in a closed loop circulation system without releasing fluid into the atmosphere and without modifying the cutting tool, it can be used as a complementary method in hybrid machining processes, as have been performed by Wang et al. [38] and Dandekar et al. [39] with cryogenic cooling and thermally assisted machining.

Acknowledgments The authors would like to thank Fundação de Amparo à Pesquisa do Estado de São Paulo (FAPESP), Brazil, for its financial support $(11 / 23600-8)$.

\section{References}

1. Bruni C, Forcellese A, Gabrielli F, Simoncini M (2006) Effect of the lubrication-cooling technique, insert technology and machine bed material on the workpiece surface finish and tool wear in finish turning of AISI 420B. Int J Mach Tool Manuf 46(12-13):15471554

2. Klocke F, EIsenblätter G (1997) Dry cutting. Ann CIRP 46:519527

3. Wichmann H, Stache H, Schmidt C, Winter M, Bock R, Herrmann C, Bahadir M (2013) Ecological and economic evaluation of a novel glycerol based biocide-free metalworking fluid. J Clean Prod 43:12-19

4. Zhao F, Ogaldez J, Sutherland JW (2012) Quantifying the water inventory of machining processes. CIRP Ann Manuf Technol 61: $67-70$

5. Burton CM, Crook B, Scaife H, Evans GS, Barber CM (2012) Systematic review of respiratory outbreaks associated with exposure to water-based metalworking fluids. Ann Occup Hyg 56(4): 374-388

6. De Groot A, Geier J, Flyvholm M, Lensen G, Coenraads P (2010) Formaldehyde-releasers: relationship to formaldehyde contact allergy. Metalworking fluids and remainder. Part 1. Contact Dermatitis 63:117-128

7. Suuronen K, Aalto-Korte K, Piipari R, Tuomi T, Jolanki R (2007) Occupational dermatitis and allergic respiratory diseases in Finnish metalworking machinists. Occup Med 57:227-283

8. Trafny EA (2013) Microorganisms in metalworking fluids: current issues in research and management. Int J Occup Med Environ Health 26(1):4-15

9. Dudzinski D, Devillez A, Moufki A, Larrouquere D, Zerrouki V, Vigneau J (2004) A review of developments towards dry and high speed machining of Inconel 718 alloy. Int J Mach Tool Manuf 44: 439-456

10. Jianxin D, Hui Z, Ze W, Yunsong L, Jun Z (2012) Friction and wear behaviors of WC/Co cemented carbide tool materials with different WC grain sizes at temperatures up to $600^{\circ} \mathrm{C}$. Int J Refract Met Hard Mater 31:196-204

11. Schaller E (1965) Einfluss der diffusion auf den Verschleiss von Hartmetallwerkzeugen bei der Zerspanung von Stahl. Ind Anz 87(9):9-14

12. Shaw MC (2005) Metal cutting principles, 2nd edn. Oxford University Press, New York, 594 p

13. Yildiz Y, Nalbant M (2008) A review of cryogenic cooling in machining processes. Int J Mach Tool Manuf 48(9):947-964

14. Dhar NR, Kamruzzaman M, Khan MMA, Chattopadhyay AB (2006) Effects of cryogenic cooling by liquid nitrogen jets on tool wear, surface finish and dimensional deviation in turning different steels. Int J Mach Mach Mater 1(1):115-135

15. Çakir O, Kiyak M, Altan E (2004) Comparison of gases applications to wet and dry cuttings in turning. J Mater Process Technol 35-41:153-154

16. Ahmed MI, Ismail AF, Nurul AKM (2007) Effectiveness of cryogenic machining with modified toolholder. J Mater Process Technol 185:91-96

17. Bouzakis K, Michailidis N, Skordaris G, Bouzakis E, Biermann D, M'saoubi R (2012) Cutting with coated tools: coating technologies, characterization methods and performance optimization. CIRP Ann Manuf Technol 61:703-723

18. Weinert K, InasakI I, Sutherland JW, Wakabayashi T (2004) Dry machining and minimum quantity lubrication. CIRP Ann Manuf Technol 53:511-537

19. Jeffries NP (1969) A new cooling method for metal-cutting tools, Ph.D. Dissertation, University of Cincinnati 
20. Jeffries NP, Zerkle RD (1970) Thermal analysis of an internallycooled metal-cutting tool. Int J Mach Tool Manuf 10:381-399

21. Zhao H, Barber GC, Zou Q (2002) A study of flank wear in orthogonal cutting with internal cooling. Wear 253:957-962

22. Zhao H, Barber GC, Zou Q, Gu R (2006) Effect of internal cooling on tool-chip interface temperature in orthogonal cutting. Tribol Trans 49:125-134

23. Chiou RY, Lu L, Chen JS, North MT (2007) Investigation of dry machining with embedded heat pipe cooling by finite element analysis and experiments. Int J Adv Manuf Technol 31:905-914

24. Al-Odat MQ (2010) Numerical analysis of cutting tool temperature in dry machining processes with embedded heat pipe. Eng Comput 27:658-673

25. Liang L, Quan Y, Ke Z (2011) Investigation of tool-chip interface temperature in dry turning assisted by heat pipe cooling. Int J Adv Manuf Technol 54:35-43

26. Rozzi JC, Sanders JK, Chen W (2011) The experimental and theoretical evaluation of an indirect cooling system for machining. $\mathrm{J}$ Heat Transf 133(3): 10p

27. Ferri C, Minton T, Ghani SBC, Cheng K (2013) Internally-cooled tools and cutting temperature in contamination-free machining. Proc Inst Mech Eng Part C J Mech Eng Sci 1-11

28. Sun X, Bateman R, Cheng K, Ghani SC (2001) Design and analysis of an internally-cooled smart cutting tool for dry cutting. Proc Inst Mech Eng B J Eng Manuf 226:585-591

29. Minton T, Ghani S, Sammler F, Bateman R, Fürstmann P, Roeder M (2013) Temperature of internally-cooled diamond-coated tools for dry-cutting titanium. Int J Mach Tool Manuf 75:27-35

30. Sanchez LEA, Scalon VL, Abreu GGC (2011) Cleaner machining through a toolholder with internal cooling. 3rd International Workshop Advances in Cleaner Production, São Paulo
31. Vicentin GC, Sanchez LEA, Scalon VL, Abreu GGC (2011) A sustainable alternative for cooling the machining processes using a refrigerant fluid in recirculation inside the toolholder. Clean Techn Environ Policy 13:831-840

32. Bhatia SM, Pandey PC, Shan HS (1978) Thermal cracking of carbide tools during intermittent cutting. Wear 51:201-211

33. Molés F, Navarro-Esbrí J, Peris B, Mota-Babilone A, Kontomaris K (2015) Thermodynamic analysis of a combined organic Rankine cycle and vapor compression cycle system activated with low temperature heat sources using low GWP fluids. Appl Therm Eng 87: 444-453

34. Komanduri R, Hou ZB (2000) Thermal modeling of the metal cutting process part I-temperature rise distribution due to shear plane heat source. Int J Mech Sci 42:1715-1752

35. Komanduri R, Hou ZB (2001) Thermal modeling of the metal cutting process part II - temperature rise distribution due to frictional heat source at the tool-chip interface. Int J Mech Sci 43:57-88

36. Komanduri R, Hou ZB (2001) Thermal modeling of the metal cutting process part III- temperature rise distribution due to the combined effects of shear plane heat source and the tool-chip interface frictional heat source. Int J Mech Sci 43:89-107

37. Lienhard JH, Eichhorn R (1976) Peak boiling heat flux on cylinders in a cross flow. Int J Heat Mass Transf 19:1135-1142

38. Wang ZY, Rajurkar KP, Fan J, Lei S, Shin YC, Petrescu G (2003) Hybrid machining of Inconel 718. Int J Mach Tool Manuf 43:13911396

39. Dandekar CR, Shin YC, Barnes J (2010) Machinability improvement of titanium alloy (Ti-6Al-4V) via LAM and hybrid machining. Int J Mach Tool Manuf 50:174-182 